\title{
Herb-induced Liver Injury in Asia and Current Role of RUCAM for Causality Assessment in 11,160 Published Cases
}

\author{
Rolf Teschke*1, Yun Zhu² and Jing Jing ${ }^{2}$ \\ ${ }^{1}$ Department of Internal Medicine II, Division of Gastroenterology and Hepatology, Klinikum Hanau, Hanau, Academic Teaching \\ Hospital of the Medical Faculty, Goethe University Frankfurt/ Main, Frankfurt/Main, Germany; ${ }^{2}$ The Fifth Medical Center, General \\ Hospital of PLA, Beijing, China
}

\begin{abstract}
Herb-induced liver injuries (HILI) by traditional herbal medicines are particular challenges in Asian countries, with issues over the best approach to establish causality. The aim of the current analysis was to provide an overview on how causality was assessed in HILI cases from Asian countries and whether the Roussel Uclaf Causality Assessment Method (RUCAM) was the preferred diagnostic algorithm, as shown before in worldwide evaluated cases of drug-induced liver injury (DILI). Using the PubMed database, publications in English language were preferred to allow for reevaluation by peers. Overall $11,160 \mathrm{HILI}$ cases have assessed causality using RUCAM and were published by first authors working in Asian countries. With 21 evaluable reports, most publications came from mainland China, with Hong Kong and Taiwan, followed by Korea $(n=15)$, Singapore $(n=2)$, and Japan $(n=1)$, while other Asian countries were not contributory. Most publications provided case and RUCAM data of good quality. For better presentation of future cases, however, the following recommendations are given: (1) preference of prospective study design with use of the updated RUCAM version; (2) clear separation of HILI cohorts from those of other herbal products or DILI; (3) case series for epidemiology studies should contain many essential data, possibly also as supplementary material; (4) otherwise, preference of single case reports providing individual case data and RUCAM-based causality gradings, and applying liver test threshold values; and (5) publication in English language journals. In conclusion, China and Korea are top in presenting RUCAM-based HILI cases, other Asian countries are encouraged to follow.

Citation of this article: Teschke R, Zhu Y, Jing J. Herb-induced liver injury in asia and current role of RUCAM for causality assessment in 11,160 published cases. J Clin Transl Hepatol 2020;8(2):200-214. doi: 10.14218/JCTH.2020.00009.
\end{abstract}

Keywords: Liver injury; Drug induced liver injury; Herb induced liver injury; RUCAM.

Abbreviations: ALP, alkaline phosphatase; ALT, alanine aminotransferase; CAM causality assessment method; DILI, drug-induced liver injury; DILIN, Druginduced Liver Injury Network; EMA, European Medicines Agency; FDA, Food and Drug Administration; GTE, green tea extracts; HEV, hepatitis E virus; HILI, herbinduced liver injury; LTs, liver tests; PAs, pyrrolizidine alkaloids; PM, Polygonum multiflorum; RCTs, randomized controlled trials; RUCAM, Roussel Uclaf Causality Assessment Method; TCM, Traditional Chinese Medicines; ULN, upper limit of normal.

Received: 4 February 2020; Revised: 5 March 2020; Accepted: 31 March 2020 * Correspondence to: Rolf Teschke, Department of Internal Medicine II, Klinikum Hanau, Teaching Hospital of the Goethe University of Frankfurt/Main, Leimenstrasse 20, D-63450 Hanau, Germany. Tel: +49-6181-21859, Fax: +49-61812964211, E-mail: rolf.teschke@gmx.de

\section{Introduction}

Herb-induced liver injury, with HILI as its acronym, was first introduced and proposed as a specific term in the scientific literature in $2011^{1,2}$ and subsequently characterized. ${ }^{3-6}$ Several review articles have addressed relevant issues of HILI also in relation with drug-induced liver injury (DILI). ${ }^{7-9}$ Evaluating suspected HILI cases is complex, complicated, and can be a tricky undertaking because herbal medications exert an intrinsic liver injury type due to overdosed ingredients or improper herbal product quality, including adulteration or toxic contamination. ${ }^{10}$ In addition, HILI emerges unpredictably in a limited number of susceptible individuals consuming herbs as medicines, based on an idiosyncratic reaction also known from drugs causing DILI. ${ }^{11}$

Contrasting to fragile HILI case evaluations in many publications, conditions are more stable for DILI by clearly defined conventional chemical drugs and the use of the Roussel Uclaf Causality Assessment Method (RUCAM) to assess causality, which has allowed an objective view on DILI characteristics based on 46,266 DILI cases published 2014-2019. ${ }^{11}$ This success was the result of DILI evaluations, which incorporated the original RUCAM of $1993,{ }^{12,13}$ an early RUCAM version of $1990,{ }^{14}$ or more recently the updated RUCAM of $2016 .{ }^{15}$ Additional information on RUCAM was provided in other publications, ${ }^{16,17}$ associated with the encouragement to strictly adhere to published criteria directed to DILI and HILI cases.

The present review focuses on published HILI cases and case series provided by authors residing in Asian countries and regions such as China, Japan, Korea, and Singapore. The principal aim was to analyze to what extent specific causality assessment methods (CAMs) like RUCAM were used to back up HILI as robust diagnosis, ensuring further case characterization.

\section{Literature search and source}

The PubMed database (1964-December 30, 2019) was searched for articles on HILI in various Asian countries by using the following terms: herb-induced liver injury, HILI, RUCAM, Roussel Uclaf Causality Assessment Method, and China, Hong Kong, Japan, Korea, India, Taiwan, Thailand, and Vietnam; search terms were used alone or in combination. With a few exceptions, the search was confined to reports in the English language. Publications of Asian authors on HILI cases that had been assessed for causality using RUCAM were individually evaluated with respect to quality of reported RUCAM data. The final compilation consisted of original papers, consensus reports, and review articles, with the most relevant publications included in the reference list. 
Teschke R. et al: HILI and RUCAM in the Asian region

\section{Definition}

HILI is clinically defined as liver injury in association with the use of an herbal product, which may include herbal medicines such as traditional herbal medicines and herbal drugs that are under regulatory surveillance. Herbal products often represent a mixture of several herbs with abundant phytochemicals as ingredients and differ thereby from DILI caused by a single chemical that is on the market after regulatory approval. Differentiation of HILI from DILI is essential and incorporating HILI among a DILI cohort is misleading, not allowing for a separate characterization of HILI features.

\section{Current state of RUCAM-based HILI reports published} from the Asian region

\section{China}

Starting as early as 2006 with an analysis from Hong Kong, ${ }^{18}$ an overall 21 reports of HILI cases were published which had been assessed for causality using RUCAM with results presented by groups with first authors having their working place in mainland China, Hong Kong, or Taiwan. ${ }^{18-38}$ These publications merit further consideration. Assessed cases were commonly well presented with respect to case data completeness and evaluation (Table 1). Most reports provided data of cohorts consisting of HILI alone, but few combined results of both HILI and DILI cases, causing confusion due to mixed data. ${ }^{24,26,30,36}$ In a few instances, publications erroneously mention in their title specifically only DILI, although HILI cases are also presented in the text, ${ }^{24,26,36}$ ignoring thereby that HILI features are clearly different from those of DILI. ${ }^{5-11}$ It seems that most reports were based on a retrospective rather than a prospective study design. Some studies included HILI cases not only with highly probable or probable causality gradings but also with a possible causality level based on RUCAM scores $\geq 3$ (Table 1). ${ }^{24,25,27,28,30,36,38}$ In other cases, RUCAM-based causality gradings were erroneously classified as definitive; ${ }^{18}$ although this term was never proposed or approved in the RUCAM literature that determines highly probable as the highest grading, ${ }^{12,15}$ the most appropriate term for results in biological systems like clinical liver injury. Occasionally, RUCAM-based causality gradings, classified initially as possible, had afterwards been upgraded to a probable level through a non-transparent maneuver ${ }^{36}$-an overall highly questionable and disputable approach as also discussed previously. ${ }^{11}$ In rare instances, causality gradings were not reported ${ }^{35}$ or RUCAM was used for causality grading but the respective publication remained unquoted, ${ }^{26,34}$ even if the updated RUCAM was mentioned in the text. ${ }^{34}$ Similar omissions of RUCAM quotation have been observed in some publications related to DILI. ${ }^{11}$

There are several excellent publications, which could serve as examples for future publications on RUCAM-based HILI cases (Table 1). The encouraging report of Zhang et al. ${ }^{29}$ analyzed HILI cases in a perfect way, using the updated RUCAM of 2016, adopting a high threshold of liver tests (LTs) to avoid nonspecific liver injuries and providing for $26 / 28$ cases a highly probable causality grading. As outlined in the report of Chau et al. ${ }^{20}$ the interrater agreement between experts and RUCAM was $81 \%$, facilitating evaluations and exclusion of cases with alternative causes or unclear herbal product identification. In general, RUCAM-based HILI series are preferred that cover in more detail a single herb, such as Gynura segetum and other pyrrolizidine alkaloids (PAs)-containing herbs like in the reports of Lin et al. ${ }^{21}$ and Gao et al. ${ }^{22,25}$ or Psoralea corylifolia like in the reports of Cheung et $a .^{19}$ and $\mathrm{Li}$ et al., ${ }^{34}$ or Polygonum multiflorum (PM), as shown in the reports of Dong et al., ${ }^{23}$ Wang et al., ${ }^{27}$ Zhu et al., ${ }^{28} \mathrm{Li}$ et al., ${ }^{31}$ Jing et al., ${ }^{33}$ and Liu et al. ${ }^{35}$ For instance, Li et al. ${ }^{31}$ presented a perfect case report on HILI caused by PM, using the updated RUCAM of $2016 .{ }^{15}$ Similarly, the case series of Dong et al. ${ }^{23}$ focuses on PM on a single herb causing HILI in 18 patients, with each having received an individual causality grading of probable or highly probable. Since for $14 / 18$ HILI patients, a highly probable causality grading was attributed, this is best explained by a careful case evaluation with complete data sets allowing for this extraordinary result. In addition and as shown in their report assessing causality by Gao et al. ${ }^{25}$ RUCAM was used for the first time in the hepatic sinusoidal obstruction syndrome caused by PAs in 23 patients, supporting the blood pyrrole-protein adducts as diagnostic biomarkers. ${ }^{25}$ The reports of Hao et al., ${ }^{24}$ Chow et al. ${ }^{32}$ and Tan et al. ${ }^{37}$ are worth mentioning because these authors clarify, already in their title, that cases had been assessed for causality using RUCAM. Tan et al. ${ }^{37}$ also carefully assessed the comedicated drug using a separate RUCAM sheet, as recommended earlier. ${ }^{12,15}$ As potential confounding alternative diagnosis, hepatitis E virus (HEV) infection was excluded in all three patients, and RUCAM-based data had been presented in a transparent list. ${ }^{37}$ In this study, most interesting was the finding of a high causality grading of probable, achieved with a score of 7; although liver injury by Swietenia macrophylla was unknown at the time of publication, providing a score of 0 , not allowing additional scores. Therefore, lack of previous knowledge of liver injury does not prevent high causality gradings. Similarly, lacking unintentional readministration, which provides a score of 0 , nevertheless allowed for a high causality grading. ${ }^{37}$ This again underscores the value of RUCAM by taking care of liver injury cases lacking some elements.

\section{Japan}

In Japan, the report of Tsuda et al. ${ }^{39}$ used the RUCAM of 1993 but there are no other RUCAM-based cases of HILI to be used for comparison with worldwide RUCAM-based HILI cases.

\section{Korea}

First authors of reports from Korea contributed as experts were numbered overall 15 , and thereby represented a substantial number of publications on 526 HILI cases that had been assessed for causality using RUCAM (Table 1). ${ }^{40-54}$ These included single case reports, case series and review articles. Respective articles were mostly of good quality, with minor shortcomings. These included, for instance, the use of a RUCAM version modified by the authors for unknown reason(s) without own method re-validation, $40,44,51,53$ the inclusion of cases with a possible causality grading that impairs the focus on cases with a probable or highly probable causality grading $40,41,42,50,52,54$ using the RUCAM algorithm but leaving individual causality grading unreported for unknown reason(s), ${ }^{51,54}$ forgetting quotation of the used RUCAM publication, ${ }^{51,54}$ and classifying the original highly probable causality grading erroneously as definite. ${ }^{47}$ It seems that most reports followed a retrospective study approach (Table 1), ${ }^{40-54}$ whereas RUCAM instructions clearly recommend the use of RUCAM for prospective studies. ${ }^{15}$ 
Teschke R. et al: HILI and RUCAM in the Asian region

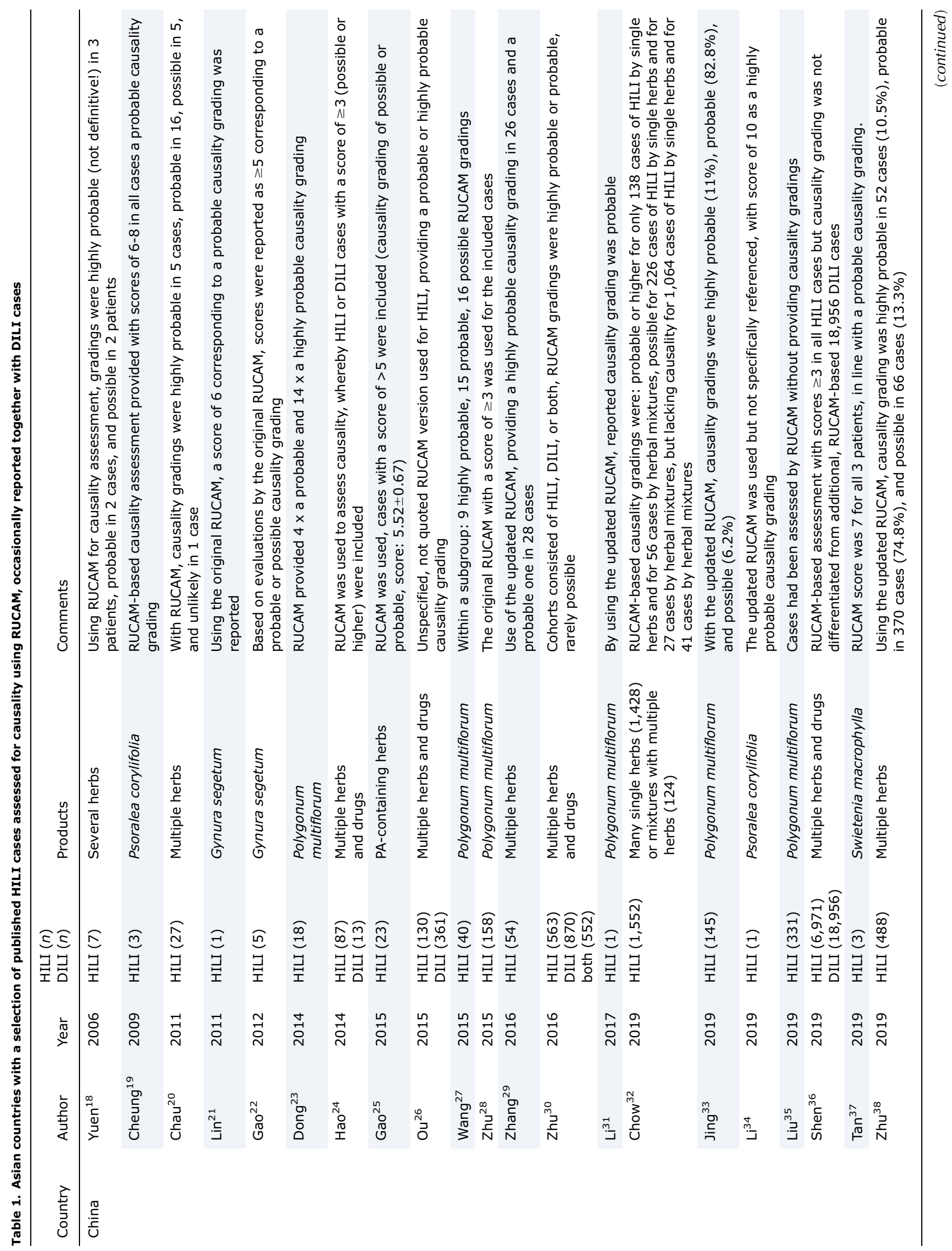


Teschke R. et al: HILI and RUCAM in the Asian region

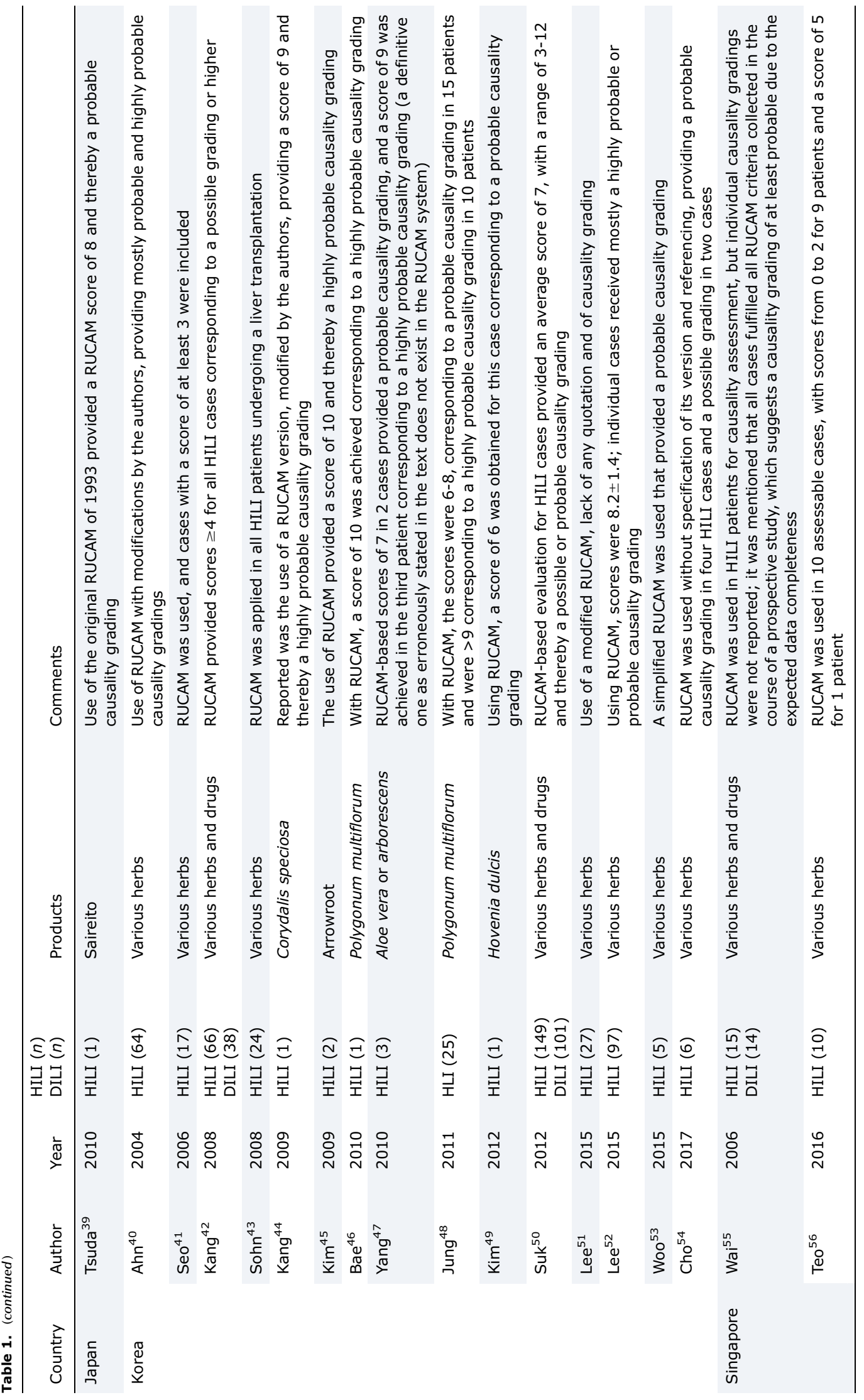


Teschke R. et al: HILI and RUCAM in the Asian region

Prefect studies were provided among others by Suk et al., ${ }^{50}$ who followed a prospective design for their nationwide HILI study in Korea, and by Kim et al. ${ }^{45}$ Bae et al., ${ }^{46}$ Yang et al., ${ }^{47}$ Jung et al., ${ }^{48} \mathrm{Kim}$ et al., ${ }^{49}$ and Woo et al., ${ }^{53}$ who all provided cases limited to a probable or highly probable causality grading, suggesting complete case data sets or prospective data collection in single case reports. Valuable is, also, the report of Kang et al., ${ }^{44}$ who described a patient with a positive re-exposure result, as evidenced by a striking increase of serum alanine aminotransferase (ALT) activity shown in a separate figure and likely following the test criteria published earlier. ${ }^{15}$

\section{Singapore}

Groups from Singapore presented two reports, with altogether 25 HILI cases that had been assessed for causality using RUCAM. ${ }^{55,56}$ In the first report published 2006 by Wai et al., ${ }^{55}$ a prospective study design was used that allowed for complete case data, conditions commonly facilitating high causality gradings. The second study published 10 years later by Teo et al. ${ }^{56}$ presented data from a retrospective analysis of spontaneous reports submitted to the national registry; respective causality gradings were extremely low due to incomplete case data, not unexpected under these study conditions.

\section{Other Asian countries}

There are virtually no valid reports on RUCAM-based HILI cases from authors residing in other Asian countries like Vietnam, Indonesia, Thailand, or India. Some reports could have been published in local language but not in English; it is also possible that RUCAM had not yet achieved a larger acceptance. With respect to RUCAM-based liver injury by Indian Ayurvedic medicines, two reports were published by authors outside of India, namely from Germany ${ }^{57}$ and the USA. ${ }^{58}$ In the report from Germany, the original RUCAM of 1993 was used and referenced for causality assessment, having provided scores of 68 as a probable causality grading for four concomitantly used herbal medicines, preferring one single herb with the highest score of $8 .{ }^{57}$ The USA report discussed RUCAM without providing a correct reference and attributed a score of 5 corresponding to a possible causality grading, ${ }^{58}$ while some questions including posology and product quality have been raised. ${ }^{59}$ It is well recognized that reports of Indian Ayurvedic medicinerelated liver injury are sparse in the literature, ${ }^{60,61}$ which we found to include not only herbs but also other complementary and alternative medicines. ${ }^{61}$ An exemption refers to 8 cases of HILI by Indian products as reported in a RUCAM-based prospective study by the Indian group of Rathi et al. ${ }^{62}$ that was classified as a report of excellence. ${ }^{63}$ With respect to Ayurvedic and herbal medicine-induced liver injury, there is a refreshing statement by Devarbhavi: ${ }^{64}$ Is it time to wake up and take notice. Indeed, the quality of HILI case evaluation is insufficient in many countries, including Asian ones, a topic that merits further discussion as outlined below.

\section{Actual issues}

\section{Increasing use of RUCAM in Asia}

There is now increasing awareness of the benefits provided by RUCAM among various countries, including China, ${ }^{18-38}$ Korea, ${ }^{40-54}$ and Singapore, ${ }^{55,56}$ as evidenced by reports initially published in 2004 from Korea ${ }^{40}$ and in 2006 from
China ${ }^{18}$ and Singapore, ${ }^{55}$ with subsequent articles (Table 1 ). On top among the Asian countries is currently China, best explained by the large population and heavy use of herbal traditional Chinese medicines (TCMs), with increasing numbers of publications and cases until 2019. ${ }^{18-38}$ Korea ranks at the second position, followed by Singapore in third place (Table 1). Scientists from other Asian countries are more cautious using RUCAM, either to avoid disturbances with the politics of the national TCM-based health system, hospital-related issues, scientific society-based requirements, or that they just prefer their own CAMs (but this should not be the preferred solution and must be declined).

\section{RUCAM essentials}

RUCAM has a remarkable scientific run among experts of HILI and RUCAM as an appreciated diagnostic algorithm for assessing causality in liver injury cases, shown alone by the large list of RUCAM-based DILI and HILI cases published until $2015 .{ }^{15}$ Additional support for RUCAM came from a recent study of 46,266 DILI cases, which had been assessed for causality using RUCAM and were published from 2014 to $2019 .{ }^{11}$ For assessing causality in DILI or HILI cases, no other method exists with such a background of worldwide use and acceptance. ${ }^{11,15}$

Appreciation of RUCAM is also substantiated by the reports evaluated for the current analysis of 11,160 HILI cases (Table 1$)^{15-56}$ that are validated by RUCAM for robust causality assessment. RUCAM is continuously used without problems ${ }^{11,15}$ except for some minor questions, addressed and clarified in previous RUCAM publications. ${ }^{15-17}$ The updated RUCAM is as good as physicians and assessors are handling this method and strictly apply published recommendations. ${ }^{15}$ RUCAM has not been designed for chronic DILI and HILI or when a suspected injury occurs on pre-existing liver disease -both complex conditions where a more accurate approach especially for the timing of the events and the exclusion of alternative causes is needed. Problems were not found at the level of RUCAM itself but rather were related to poor quality case data or the users if they publish incorrect RUCAM-based causality gradings that had been lifted intentionally from possible to probable gradings. Otherwise, a recent analysis showed that RUCAM performs well provided the RUCAM users do a good job. ${ }^{11}$

The philosophy behind creating the original RUCAM of 1993 was to facilitate a valid diagnosis for patients with suspected liver injury. This led to the development of a liver-specific, quantitative, objective, transparent, and structured diagnostic algorithm ${ }^{12}$ which was well validated using cases with positive re-exposure tests as gold standard. ${ }^{13}$ An update was published later, ${ }^{15}$ with two different scales, one for cases of hepatocellular injury (Table 2) and one for the cholestatic or mixed liver injury (Table 3 ) ${ }^{15}$ This updated RUCAM is now in common use and should be applied for future cases replacing earlier versions. ${ }^{12,14}$ Occasionally, groups reported the use of RUCAM versions with their own unclear modifications (Table 1), but this attempt must be rejected because such modifications would require a new method validation that has never been provided. A clear unmodified diagnostic algorithm, such as the updated RUCAM of 2016, is essential for complex diseases, as are DILI and HILI, to avoid subjective evaluations and arbitrary conclusions; the RUCAM-based method uniformity will allow 
Teschke R. et al: HILI and RUCAM in the Asian region

Table 2. RUCAM worksheet for hepatocellular injury

Suspected product:

Items for hepatocellular injury

Date:

\begin{tabular}{ll}
\hline Score & Result \\
+2 & $\square$ \\
+1 & $\square$ \\
+1 & $\square$
\end{tabular}

1. Time to onset from the beginning of the drug/herb

- 5-90 days (rechallenge: 1-15 days)

- $<5$ or $>90$ days (rechallenge: $>15$ days)

Alternative: Time to onset from cessation of the drug/herb

- $\leq 15$ days (except for slowly metabolized chemicals: >15 days)

2. Course of ALT after cessation of the drug/herb

\section{Percentage difference between ALT peak and ULN}

- Decrease $\geq 50 \%$ within 8 days

- Decrease $\geq 50 \%$ within 30 days

- No information or continued drug use

- Decrease $\geq 50 \%$ after the 30th day

- Decrease $<50 \%$ after the 30th day or recurrent increase

\section{Risk factors}

- Alcohol use (current drinks/day: $>2$ for women, $>3$ for men)

- Alcohol use (current drinks/day: $\leq 2$ for women, $\leq 3$ for men)

- Age $\geq 55$ years

- Age $<55$ years

\section{Concomitant drug(s)/herb(s)}

- None or no information

- Concomitant drug/herb with incompatible time to onset

- Concomitant drug/herb with time to onset 5-90 days

- Concomitant drug/herb known as hepatotoxin and with time to onset 5-90 days

- Concomitant drug/herb with evidence for its role in this case (positive rechallenge or validated test)

\section{Search for alternative causes Group I (7 causes)}

- HAV: Anti-HAV-IgM

- HBV: HBsAg, anti-HBc-IgM, HBV-DNA

- HCV: Anti-HCV, HCV-RNA

- HEV: Anti-HEV-IgM. anti-HEV-IgG, HEV-RNA

- Hepatobiliary sonography / Doppler / CT /MRC

- Alcoholism (AST/ALT $\geq 2$ )

- Acute recent hypotension history (particularly if underlying heart disease)

Group II ( 5 causes)

- Complications of underlying disease(s), such as sepsis, metastatic malignancy, autoimmune hepatitis, chronic hepatitis B or C, primary biliary cholangitis or sclerosing cholangitis, genetic liver diseases

- Infection suggested by PCR and titer change for

- CMV: anti-CMV-IgM, anti-CMV-IgG

- EBV: anti-EBV-IgM, anti-EBV-IgG

- HSV: anti-HSV-IgM, anti-HSV-IgG

- VZV: anti-VZV-IgM, anti-VZV-IgG

+3
+2
0
0
-2

$\begin{array}{ll}+1 & \\ 0 & \\ +1 & \\ 0 & \end{array}$

Evaluation of groups $I$ and II

- All causes-groups I and II - reasonably ruled out

0

0

$-1$

$-2$

$-3$

$-3$ 
Teschke R. et al: HILI and RUCAM in the Asian region

Table 2. (continued)

\begin{tabular}{|c|c|c|}
\hline \multirow{2}{*}{$\begin{array}{l}\text { Suspected product: } \\
\text { Items for hepatocellular injury }\end{array}$} & \multicolumn{2}{|l|}{ Date: } \\
\hline & Score & Result \\
\hline - The 7 causes of group I ruled out & +1 & $\square$ \\
\hline - 6 or 5 causes of group I ruled out & 0 & $\square$ \\
\hline - Less than 5 causes of group I ruled out & -2 & $\square$ \\
\hline - Alternative cause highly probable & -3 & $\square$ \\
\hline \multicolumn{3}{|l|}{ 6. Previous hepatotoxicity of the drug/herb } \\
\hline - Reaction labelled in the product characteristics & +2 & $\square$ \\
\hline - Reaction published but unlabeled & +1 & $\square$ \\
\hline - Reaction unknown & 0 & $\square$ \\
\hline \multicolumn{3}{|l|}{ 7. Response to unintentional reexposure } \\
\hline - Doubling of ALT with the drug/herb alone, provided ALT below $5 \times$ ULN before reexposure & +3 & $\square$ \\
\hline - Doubling of ALT with the drug(s)/herb(s) already given at the time of first reaction & +1 & $\square$ \\
\hline - Increase of ALT but less than ULN in the same conditions as for the first administration & -2 & $\square$ \\
\hline - Other situations & 0 & $\square$ \\
\hline \multicolumn{3}{|l|}{ Total score } \\
\hline
\end{tabular}

Adapted from a previous report of Danan and Teschke, $2016 .^{15}$

The above items specifically refer to the hepatocellular injury rather than to the cholestatic or mixed liver injury (shown in Table 3 ).

Total score and resulting causality grading: $\leq 0$, excluded; $1-2$, unlikely; $3-5$, possible; $6-8$, probable; $\geq 9$, highly probable.

Abbreviations: ALT, alanine aminotransferase; AST, aspartate aminotransferase; CMV, cytomegalovirus; CT, computed tomography; EBV, Epstein-Barr virus; HAV, hepatitis A virus; $\mathrm{HBC}$, hepatitis B core; HBsAg, hepatitis B antigen; HBV, hepatitis B virus; HCV, hepatitis C virus; HEV, hepatitis E virus; HSV, Herpes simplex virus; MRC, magnetic resonance cholangiography; ULN, upper limit of the normal range; RUCAM, Roussel Uclaf Causality Assessment Method; VZV, Varicella zoster virus.

for valid comparison of case results between countries and continents.

RUCAM evaluates seven key elements characteristic for liver injury, which are individually scored, and their summed score provides a final score and a final causality grading; ${ }^{15}$ for instance, final score of $\leq 0$ excludes causality, of $1-2$ is unlikely, of $3-5$ is possible, of $6-8$ is probable, and $\geq 9$ is highly probable. The highest RUCAM-based causality level is not definite as erroneously described in some publications (Table 1 ) but clearly termed as highly probable, ${ }^{15}$ respecting the biological nature-based variability of liver injury and the associated lack of any definite or certain condition. In general, the highest final scores and associated high causality gradings are obtained with complete case data sets and are best achieved by a prospective study design as the primary aim of any causality assessment of liver injury cases. ${ }^{15}$ However, and if worse comes to worst, RUCAM is also applicable and prepared for liver injury cases assessed retrospectively, but this commonly leads to low final RUCAM scores and low causality gradings because RUCAM partially disqualifies missing data by low or negative scores to be subtracted from the final score. Low final scores often provide a possible causality grading, and respective cases should not be included in study cohorts of cases with a probable or highly probable causality grading, just to avoid a mix of cases with different causality gradings. Describing clinical features of liver injury cases should be based exclusively on cases with a probable or highly probable causality grading of RUCAM. This certainly applies for evaluations and descriptions of any new diagnostic biomarker, as well. ${ }^{65}$ Some diagnostic biomarkers are well established for HILI and DILI, but others came under scientific fire due to recent actions of the European Medicines
Agency (known as the EMA) through the correct and official retraction of its earlier Letter of Support to promote biomarker research and use. ${ }^{65}$ The retraction by EMA was the consequence of faulty results based on studies misconducted by not-further identified liver injury experts. ${ }^{11,65}$ This official retraction represents currently, and in near future, a tricky dilemma for the scientific liver injury community.

Additional notes on HILI in Asia or elsewhere relating to RUCAM are warranted for reasons of clarity and transparency. ${ }^{66-71}$ A report of excellence is the careful systematic review on Chinese HILI and the use of RUCAM in 54 cases with high causality gradings, published by Zhang et al. ${ }^{29} \mathrm{~A}$ robust diagnostic algorithm, such as RUCAM, is commonly used in cases of DILI ${ }^{11}$ and HILI by TCMs, ${ }^{18-62,66}$ with more details provided in a recent systematic review on clinical characteristics and outcomes. ${ }^{66}$ This analysis compares the quality of three RUCAM-based study cohorts, preferring studies of single case reports which provide clinical data and RUCAM details of each patient with HILI by TCMs. The second choice are studies, which summarize the data of a series of patients with HILI by TCM. The third choice refers to studies of extremely low quality, which report the proportion of HILI by TCM in a mix with all DILI cases. This analysis also showed, for study cohorts with a fairly good case data quality, that RUCAM was used as a diagnostic tool in 97/203 studies (47.8\%), whereby $154 / 203$ studies $(75.9 \%)$ were published in Chinese-language journals, which lacked individual references not open for re-evaluation by peers and without causality gradings; only $2 / 203$ studies were prospective. ${ }^{66}$ Consequently, over half of the studies published in China did not benefit from a good CAM, calling for substantial improvement in future cases. Shortcomings are also evident in a USA 
Teschke R. et al: HILI and RUCAM in the Asian region

Table 3. RUCAM worksheet for cholestatic or mixed liver injury

Suspected product:

Items for cholestatic or mixed liver injury

Date:

1. Time to onset from the beginning of the drug/herb

- 5-90 days (rechallenge: 1-90 days)

- $<5$ or $>90$ days (rechallenge: $>90$ days)

Alternative: Time to onset from cessation of the drug/herb

- $\leq 30$ days (except for slowly metabolized chemicals: $>30$ days)

Score
+2
+1
+1
+2
+1
0

2. Course of ALP after cessation of the drug/herb

Percentage difference between ALP peak and ULN

- Decrease $\geq 50 \%$ within 180 days

- Decrease $<50 \%$ within 180 days

- No information, persistence, increase, or continued drug/herb use

\section{Risk factors}

- Alcohol use (current drinks/day: $>2$ for women, $>3$ for men)

- Alcohol use (current drinks/day: $\leq 2$ for women, $\leq 3$ for men)

- Pregnancy

- Age $\geq 55$ years

- Age $<55$ years

+1
0
+1
+1
0

\section{Concomitant use of drug(s)/herb(s)}

- None or no information

- Concomitant drug/herb with incompatible time to onset

- Concomitant drug/herb with time to onset 5-90 days

- Concomitant drug/herb known as hepatotoxin and with time to onset 5-90 days

- Concomitant drug/herb with evidence for its role in this case (positive rechallenge or validated test)

\section{Search for alternative causes}

Group I (7 causes)

- HAV: Anti-HAV-IgM

- HBV: HBsAg, anti-HBC-IgM, HBV-DNA

- HCV: Anti-HCV, HCV-RNA

- HEV: Anti-HEV-IgM, anti-HEV-IgG, HEV-RNA

- Hepatobiliary sonography / Doppler / CT / MRC

- Alcoholism (AST/ALT $\geq 2$ )

- Acute recent hypotension history (particularly if underlying heart disease)

Group II (5 causes)

- Complications of underlying disease(s), such as sepsis, metastatic malignancy, autoimmune hepatitis, chronic hepatitis $\mathrm{B}$ or $\mathrm{C}$, primary biliary cholangitis or sclerosing cholangitis, genetic liver diseases

- Infection suggested by PCR and titer change for

- CMV: anti-CMV-IgM, anti-CMV-IgG

- EBV: anti-EBV-IgM, anti-EBV-IgG

- HSV: anti-HSV-IgM, anti-HSV-IgG

- VZV: anti-VZV-IgM, anti-VZV-IgG

Evaluation of group I and II

- All causes - groups I and II - reasonably ruled out

- The 7 causes of group I ruled out

\begin{tabular}{|c|c|}
\hline 0 & $\square$ \\
\hline 0 & $\square$ \\
\hline-1 & $\square$ \\
\hline-2 & $\square$ \\
\hline-3 & $\square$ \\
\hline $\begin{array}{l}\text { Tick if } \\
\text { negative }\end{array}$ & $\begin{array}{l}\text { Tick if } \\
\text { not } \\
\text { done }\end{array}$ \\
\hline 口 & $\square$ \\
\hline$\square$ & $\square$ \\
\hline 口 & $\square$ \\
\hline 口 & $\square$ \\
\hline$\square$ & $\square$ \\
\hline$\square$ & $\square$ \\
\hline$\square$ & $\square$ \\
\hline$\square$ & 口 \\
\hline$\square$ & 口 \\
\hline$\square$ & $\square$ \\
\hline$\square$ & $\square$ \\
\hline$\square$ & 口 \\
\hline+2 & $\square$ \\
\hline+1 & $\square$ \\
\hline
\end{tabular}


Table 3. (continued)

\begin{tabular}{|c|c|c|}
\hline \multirow{2}{*}{$\begin{array}{l}\text { Suspected product: } \\
\text { Items for cholestatic or mixed liver injury }\end{array}$} & \multicolumn{2}{|l|}{ Date: } \\
\hline & Score & Result \\
\hline - 6 or 5 causes of group I ruled out & 0 & $\square$ \\
\hline - Less than 5 causes of group I ruled out & -2 & $\square$ \\
\hline - Alternative cause highly probable & -3 & $\square$ \\
\hline \multicolumn{3}{|l|}{ 6. Previous hepatotoxicity of the drug/herb } \\
\hline - Reaction labelled in the product characteristics & +2 & $\square$ \\
\hline - Reaction published but unlabeled & +1 & $\square$ \\
\hline - Reaction unknown & 0 & $\square$ \\
\hline \multicolumn{3}{|l|}{ 7. Response to unintentional reexposure } \\
\hline - Doubling of ALP with the drug/herb alone, provided ALP below $2 \times U L N$ before reexposure & +3 & $\square$ \\
\hline - Doubling of ALP with the drugs(s)/herbs(s) already given at the time of first reaction & +1 & $\square$ \\
\hline - Increase of ALP but less than ULN in the same conditions as for the first administration & -2 & $\square$ \\
\hline - Other situations & 0 & $\square$ \\
\hline \multicolumn{3}{|l|}{ Total score } \\
\hline
\end{tabular}

Adapted from a previous report of Danan and Teschke, $2016 .^{15}$

The above items specifically refer to the cholestatic or mixed liver injury rather than to the hepatocellular injury (shown in Table 2 ).

Total score and resulting causality grading: $\leq 0$, excluded; $1-2$, unlikely; $3-5$, possible; $6-8$, probable; $\geq 9$, highly probable.

Abbreviations: ALP, alkaline phosphatase; ALT, alanine aminotransferase; AST, aspartate aminotransferase; CMV, Cytomegalovirus; CT, computed tomography; DILI, EBV, Epstein-Barr virus; HAV, hepatitis A virus; HBc, hepatitis B core; HBsAg, hepatitis B antigen; HBV, hepatitis B virus; HCV, hepatitis C virus; HEV, hepatitis E virus; HSV, Herpes simplex virus; MRC, magnetic resonance cholangiography; ULN, upper limit of the normal range; RUCAM, Roussel Uclaf Causality Assessment Method; VZV, Varicella zoster virus.

Food and Drug Administration (FDA) study, which discusses issues of HILI and used the method of the Drug-Induced Liver Injury Network (DILIN) ${ }^{67}$ for causality assessment, which comes along without any specific element scoring and provides only arbitrary causality gradings as percentage ranges; ${ }^{68}$ additionally, other CAMs were used, ${ }^{67}$ known for being not specific for liver injury cases and not based on typical, individually scored liver-related key elements, as amply discussed previously ${ }^{15}$ and reiterated recently. ${ }^{68}$ No question, the strength of this FDA report would have been increased if the updated RUCAM of $2016^{15}$ would have been used rather than just referencing publications on RUCAM. ${ }^{67}$ Critical is also the data source of used cases, which were partially retrieved from the USA's National Institutes of Health LiverTox database, ${ }^{67}$ known for inclusion of liver injury cases lacking robust CAMs and being therefore disputed. ${ }^{69-71}$

\section{Liver test thresholds}

Liver injury is defined by increased serum activities of LTs: ALT of at least 5 times the upper limit of normal (ULN) and/or of alkaline phosphatase (ALP) of at least $2 \times U L N$, best assessed simultaneously on the day of first presentation, as outlined in $2016 .{ }^{15}$ In the original RUCAM of 1993, ALT thresholds were lower, with at least $2 \times \mathrm{ULN},{ }^{13}$ but should not be applied anymore to ensure exclusion of unspecific liver injury cases. ${ }^{15}$ The currently favored ALT and ALP threshold values of $2016^{15}$ have also been considered as perfect in China by Yang et al. ${ }^{72}$ Therefore, and for reasons of comparability, in future publications on HILI, the use of the current thresholds and their mentioning in the text is urgently recommended, namely ALT $\geq 5 \times U L N$ and ALP $\geq 2 \times U L N$. In fact, actual threshold information is often lacking in HILI publications (Table 1). ${ }^{18-56}$ Disregarding thresholds impedes clear differentiation between liver injury and LTabnormality. ${ }^{51}$ As expected, increasing ALT thresholds from $\geq 3 \times U L N$ to $\geq 5 \times$ ULN substantially reduces the case number of true HILI. ${ }^{73}$

\section{Causality grading}

RUCAM-based causality gradings are defined with highly probable being the top level. ${ }^{15}$ Attempts to modify the commonly used RUCAM gradings must be resisted. For instance, efforts to use the RUCAM gradings concomitantly with the arbitrary percentage ranges of causality gradings have been published, so far being favored by the disputable vague DILIN system, and to incorporate it in the RUCAM algorithm ${ }^{74}$-an approach that will not work. Just the opposite direction should be taken by incorporating the RUCAM-based scoring system in the DILIN method, rendering it then an excellent quantitative CAM, unrelated to the intransparent, subjective global introspection method used currently in the USA. Problematic are also post hoc uptonings of RUCAM-based causality gradings from possible up to probable. ${ }^{36}$ In addition and as confirmed in court, intentional uptonings of RUCAM scores from possible to probable gradings invalidate published conclusions, ${ }^{75,76}$ disregarding ethics among the scientific community. ${ }^{11}$

\section{Epidemiology}

Epidemiology aspects of liver injury remain an issue. ${ }^{51,54,73,77,78}$ A low HILI prevalence was found in a large retrospective single center study from Korea, in which $27 / 4769$ patients $(0.6 \%)$ with musculoskeletal disorders 
received TCMs, as reported by Lee et al., ${ }^{51}$ with confirmed results through secondary evaluation by the same group. ${ }^{73}$ For Korea again, Cho et al. ${ }^{54}$ reported HILI prevalence results from a nationwide multicenter and prospective study with $6 / 1001$ patients $(0.6 \%)$. These results, from one single country and presented by two different groups, are surprising and require comments. With $0.6 \%$, identical data of HILI prevalence were achieved; ${ }^{51,54,73}$ although, one group used a retrospective design, commonly known for its low case quality, ${ }^{51,73}$ whereas the other group followed a prospective protocol. ${ }^{54}$ The low prevalence data were achieved by both groups using HILI cases with ALT thresholds of at least $3 \times$ ULN, which included many cases with unspecific LT increases. ${ }^{51,54,73}$ With higher ALT thresholds of $\geq 5 \times U L N$, HILI case numbers approached the zero range, ${ }^{73}$ signifying that all is now perfectly done, with reasonable results and without the need of further studies. Indeed, since 2017, no other HILI-related reports were published from Korea (Table 1). HILI is seemingly not a problem in Korea, $51,54,73$ similar to Germany, considering the low TCM-related HILI incidence data. ${ }^{77}$ In that report, liver injury data were derived from a prospective, hospital-based and large-scale study of 21,470 patients who had no liver disease prior to treatment with herbal TCM. Among these, 26 patients $(0.12 \%)$ experienced HILI on formal grounds, as evidenced by ALT values of $\geq 5 \times U L N$, but a probable causality was attributable to only $8 / 26$ cases, a possible one to $16 / 26$ patients, and an excluded one to $2 / 26$ cases, using the updated RUCAM. ${ }^{77}$

In China, with around 1.4 billion inhabitants, ${ }^{36}$ conditions of HILI are more complex. ${ }^{36,78}$ In particular, valid epidemiology data of HILI are not available for the population; although, herbal TCMs are integral constituents of the Chinese health system. An earlier vain epidemiology analysis was not RUCAM-based and used mixed cohorts of injury cases by drugs, herbs, or CAMs. ${ }^{78}$ Instead, some improvements were evident in a more recent report, with the title focusing on incidence and etiology of DILI in mainland China, published in a 2019 issue of Gastroenterology. ${ }^{36}$ At least, it was now recognized that the use of RUCAM, as a valuable diagnostic algorithm, can help assess causality in liver injury cases. ${ }^{36}$ However, the respective cohorts were grouped under the term of DILI, and represented still not only DILI but also liver injury cases caused by herbal TCM and herbal dietary supplements, representing two different product categories and again providing conditions similar to the shortcomings of the earlier study ${ }^{78}$ and not allowing for characterization of HILI epidemiology features. ${ }^{36}$ Nevertheless, some progress is recognizable because other critical shortcomings have been well identified in the text under the limitation section. ${ }^{36}$ What's more important, a new version of this study was already promised and will hopefully be published with inclusion of the updated RUCAM of 2016, now being without major flaws and after more careful peer reviews, preventing letters to the Editor. Under the current conditions, no valid statement is warranted on HILI epidemiology in China. ${ }^{36}$ Nevertheless, China is well prepared to present valid data on HILI cases, all assessed by RUCAM, as listed in Table 1 and referenced. ${ }^{18-38}$

For future studies on epidemiology, a reminder may be useful: epidemiology includes incidence and prevalence; hence, these two parameters are to be considered separately. ${ }^{79}$ The incidence of HILI and, of course, DILI is expressed as the total number of new injury cases during a certain period of time, divided by the number of individuals in the population initially at risk. The prevalence of liver injury by herbs or drugs is calculated as the total number of liver injury cases in the population at a given time, and it represents an estimate of how common liver injury can affect the general population at a fixed time. Consequently, incidence commonly provides information about the risk of acquiring new liver injury; whereas, prevalence signifies how widespread liver injury from herbs or drugs is. Prospective studies will provide best results on the incidence.

\section{Case data quality}

With a good study design, high-quality HILI cases are to be expected. ${ }^{15-17}$ Only a prospective study design that includes the use of the updated RUCAM ${ }^{15}$ will provide valid and complete data of HILI cases, with a high causality grading of probable or better highly probable. Case presentation should follow few principles. ${ }^{80}$ No question, the updated RUCAM can be used even for HILI cases obtained from retrospective studies; although, this is not the preferred approach. Based on the present experience, editors of journals should prefer publication of only articles dealing with HILI cases presenting good case data quality obtained prospectively using the updated RUCAM.

\section{Herbal product quality}

Basic requirements: Whenever a patient with assumed HILI is further evaluated clinically, one of the key questions relates to product quality, including herb authentication (Table 4). RUCAM is not destined to check for product quality. Of concern are impurities and adulteration by synthetic drugs that might have been added erroneously or intentionally to increase the efficacy of the herbal product. ${ }^{10,79}$ The quality of herbal medicines must be evaluated by toxicology methods, such approach is a routine measure in a TCM hospital in Germany, as described previously. ${ }^{77}$ In this clinical setting, only herbal TCMs of verified quality are used by the patients under care, raising the question of whether this quality concept contributes to the low number of HILI cases observed under these specific hospital conditions. In addition, the quality of herbs is influenced by other factors $^{79}$ that are rarely considered in HILI case analyses published in Asian countries ${ }^{18-56}$ or elsewhere, including those in the recent Special Issue on "Drug, Herb, and Dietary Supplement Hepatotoxicity", which presented much information in various articles on liver injury by herbal products. ${ }^{81}$ Therefore, these important and so far largely neglected aspects are discussed in much more detail below.

Plant circadian clock system: The Nobel Prize in Physiology or Medicine 2017 was awarded to the three US scientists Michael W. Young, Michael Rosbash, and Jeffrey C. Hall for their discoveries on the molecular mechanisms controlling circadian rhythms (the physiological 24-hour body clock). ${ }^{82}$ Their discoveries explain how plants, animals, and humans adapt their biological rhythm so that it is synchronized with the Earth's revolutions. They identified a gene which encodes a protein within the cell during the night that then degrades during the day. Sufficient evidence exists to mandate understanding plant physiology and consideration of plant circadian rhythm in manufacture of good quality herbal products. ${ }^{82,83}$ In experimental studies using plant leaves and mimicking the daylight, exposure of ultraviolet-C (short wavelength) to the 
Teschke R. et al: HILI and RUCAM in the Asian region

Table 4. Proposal for good quality of herbal medicines, safe use, and requirements for regulatory approved herbal drugs

Specific international qualification required for regulatory approved herbal drugs

- Good Agricultural Practices

- Good Manufacturing Practices

- Definition of plant family, subfamily, species, subspecies, and variety

- Definition of plant part

- Definition of solvents and solubilizers

- Lack of impurities, adulterants, and misidentifications

- Minimum of batch and product variability

- Lack of variety to variety variability

- Brand name with details of ingredients, plant parts, batch number, and expiration date

- Manufacturer with address

- Regulatory specification of indication of herbal drug use

- Daily dose with details of the application form

- Maximum duration of herbal drug use

- Efficacy of the herbal drug proven by valid randomized controlled trials

- Description of adverse reactions and their frequency

- Information of risk/benefit profile

- Internationally approved regulatory surveillance

- Regulatory harmonization to use the updated RUCAM in order to assess causality in suspected HILI cases

Abbreviations: HILI, herb-induced liver injury; RUCAM, Roussel Uclaf Causality Assessment method.

Shell ginger (Alpinia zerumbet) of the ginger family (Zingiberaceae) modulates the relative chemical composition, changes the amounts of essential oils and total phenols, and alters the antioxidant activity. ${ }^{83}$ The circadian clock system in plants controls many important metabolic pathways and functions, including photosynthesis, stomatal opening, and molecular processes leading to gene expression. ${ }^{82}$ Transcriptional, translational, and post-translational processes are interlocked by feedback loops among morning- and eveningphased genes. ${ }^{83}$ Changing circadian rhythms may be an approach to gain improved plant quality, to prevent poor quality, or both. ${ }^{82,83}$ Better identifying their pathways and processes that are clock controlled and of benefit for the plants, ${ }^{84}$ however, is still a major multidisciplinary challenge of plant chronobiology.

Plant stress: Herbal product quality is also modified by biotic or abiotic plant stress, affecting higher plants. ${ }^{79}$ Biotic plant stress by pathogen attacks of other living organisms is caused by insects, larger grazing animals, parasites, bacteria, viruses, and fungi. Instead, abiotic stress is caused by environmental attacks, heavy ultraviolet radiation, draft, wounding, or soil contamination by salts or heavy metals. ${ }^{83,85,86}$ At the molecular level, plant stress leads to oxidative stress through generation of reactive oxygen species, damaging the plant's integrity and impairing herbal product quality. This is triggered if radical scavenging chemicals, such as polyphenols, are absent in the plant under injurious stress.

Seasonal variation: Herbal quality is strongly dependent on the harvest time, shown recently as example for the roots of Cyathula officinalis, a popular TCM. ${ }^{87}$ Using a metabolomic approach based on gas chromatography-mass spectroscopy, 166 metabolites had been identified in these roots, 63 of which showed significant quantitative changes in different growth years of up to 4 years. It was suggested to harvest in the fourth grow year in order to boost herbal quality, and extending these studies to other plants. ${ }^{87}$ Such studies about variation of phytochemicals in different harvest times is in line with Good Agricultural Practice standards of Chinese traditional herbs in China. Fixing the harvest year will provide consistency of batches and herbal products with the desired phytochemicals as target ingredients.

Area of harvest: Unexpected were results obtained with PM, harvested from various regions of China and assessed for its hepatotoxic potential. ${ }^{88}$ This is an important study, since PM is much used in China and elsewhere, and known for its liver toxicity. These results showed that liver toxicity was obviously different among the various areas of harvest, and the most toxic PM was from the Sichuan Province. It is noteworthy that emodin was not considered the main hepatotoxin anymore, as opposed to previous studies. ${ }^{88-90}$ Preference is now given to both tetrahydroxystilbene-O-(galloyl)-hex and emodin-O-hex-sulfate as the primary offending agents. ${ }^{88}$

Case and herb listing: An optimum listing of several individual Asian herbs causing HILI should include cases with RUCAM-based causality assessment and high causality grading. Respective lists presented by authors of Asian countries in English language are scarce, partly due to the focus on DILI cases with neglect of HILI data (Table 1). ${ }^{18-56}$ Similarly, in one of the largest studies of DILI with HILI published within the last year, little attention was paid to a separate robust listing of herbs causing liver injury in China. ${ }^{37}$ Instead, a comprehensive list was provided by the exceptional study of Zhang et al. ${ }^{29}$

A few publications from authors outside of Asia have presented some case and herb listings of Asian HILI but with limited information. For instance, our group published initial lists of HILI by various herbal TCMs, with partially incomplete data regarding causality grading, RUCAM use, or quotation of respective reports. ${ }^{15,89-95}$ In one publication of 2014, HILI lists contained herbal TCMs, references, and data of causality assessments using criteria of re-exposure tests but RUCAM-based causality gradings were not provided. ${ }^{91}$ In the other report, these gradings were provided for a few HILI cases. ${ }^{92}$ Reports of 2015 presented HILI lists of TCM herbs with established causality ${ }^{93}$ or a large list of herbal TCMs causing HILI with exact case numbers but without RUCAMbased causality grading. ${ }^{94} \mathrm{~A}$ large list with individual RUCAM-based causality grading for various herbal TCMs was 
also published. ${ }^{95}$ Reports of 2016 presented case lists of HILI with TCM herbs and causality assessment by RUCAM or positive re-exposure tests ${ }^{89}$ or a country-wise case listing of HILI by herbal TCMs with exact numbers and references, ${ }^{90}$ and a large list of RUCAM-based injury cases by herbal TCMs, other herbs and drugs, all listed within the publication of the updated RUCAM. ${ }^{15}$ From outside of Asia, reports were published by authors of the USA on a few cases of HILI by TCMs. ${ }^{3,67}$ The large group of cases included in the first USA report would have benefitted if better stratified regarding RUCAM assessment. ${ }^{3}$ In contrast, cases presented by the second group of the USA FDA ${ }^{67}$ were partially assessed using the updated RUCAM ${ }^{15}$ or a unique, not validated evidence-based method. Cases were also derived from the LiverTox database, ${ }^{67}$ with its published problems in assessing a correct causality in liver injury cases. ${ }^{69-71}$ Data were also disappointing in another FDA report with attempted focus on the development of a database for herbal and dietary supplement-induced liver toxicity, but herbal TCMs and causality assessment by the updated RUCAM were explicitly not considered. ${ }^{96}$

Not included in this analysis were cases of HILI in association with the use of products derived from Camellia sinensis, consumed either as green tea beverage or green tea extracts (GTE) because respective publications by Asian authors are scarce; indeed, it is mainly a problem in Western countries, where many RUCAM-based reports were published on liver injury in connection with the use of GTE. ${ }^{97,98}$ Key issues around liver injury by GTE are obviously settled now, as the United States Pharmacopeia and DILIN members finally made it and confirmed that GTE are potentially hepatotoxic by using the updated RUCAM and thereby breaking boundaries to good medicine based on evidence and a diagnostic algorithm in line with artificial intelligence proposals. $^{99}$

Networks and regulatory databases: Generally problematic are reports presented as network data when case presentations and causality assessments are poor. $67,96,100$ For instance, a network-based pharmacology study of the HILI potential of traditional hepatoprotective Chinese herbal medicines discusses aspects of liver injury without considering issues of causality assessment like the use of the updated RUCAM. ${ }^{100}$ Clearly, shortcomings of methodological requirements invalidate studies like this one. Unexpectedly, not a single case of HILI was found in a retrospective study of adverse events due to complementary health products in Singapore from 2010 to 2016; adverse events were reported to the Health Sciences Authority, and analyzed were overall 147,215 adverse event reports suspected to be associated with pharmaceutical products and complementary health products, which included Chinese traditional medicines. ${ }^{101}$ These data are at variance with another Singapore study of liver injury associated with CAM-a review of adverse event reports in an Asian community from 2009 to 2014, in which 10 assessable HILI cases provided weak RUCAM scores from 0 to 2 for 9 patients and a score of 5 for 1 patient. ${ }^{56}$ In another report from Singapore, RUCAM was used in 15 HILI patients for causality assessment, whereby all cases reportedly fulfilled all RUCAM criteria but individual RUCAM-based causality gradings were not reported. ${ }^{55}$ Data were collected in the course of a prospective study which suggest a causality grading of at least probable due to the expected data completeness. These data again underscore the complexity of accessing valid
HILI data within a single country, but the overall conclusion can be reached that HILI is rare in Singapore. The reasons of these promising data are possibly related to the herbal product quality. ${ }^{101}$

\section{Current and resolved controversies}

In Korea, a HILI report published in $2015^{51}$ contained shortcomings regarding the use of RUCAM (Table 1 ). There was intermittently a heavy dispute on the low HILI case frequency-forced by scientific societies, TV, and print press, and overall poor conditions for scientific discussions-but reevaluation confirmed the initial conclusions and likely settled the disturbances, for now. ${ }^{73}$ Focusing on another report ${ }^{36}$ and the related Letters to the Editor ${ }^{102-104}$ by various DILI experts from China, ${ }^{102,104}$ India, ${ }^{103}$ and Iceland, ${ }^{103}$ discussions have emerged around the reported RUCAM-based DILI and HILI cases $^{36}$ but it seems that the problems can well be solved in a new, promised prospective study, whereby the use of RUCAM may again be helpful, now applying its updated version. ${ }^{36,102-105}$ The cited problems focused, among others, on the retrospective design of the study ${ }^{36}$ and it was argued that results gathered retrospectively do not allow valid conclusions. ${ }^{102-104}$ This is why the updated RUCAM calls for prospective use. ${ }^{15}$

\section{Guidelines}

For China, guidelines exist with focus on the diagnosis of HILI (Fig. 1), ${ }^{106}$ HILI by herbal TCMs, ${ }^{107}$ and DILI. ${ }^{108}$ Several

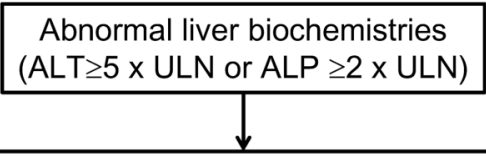

Detailed history, physical examination, laboratory tests and imaging tests, or liver biopsy, if necessary

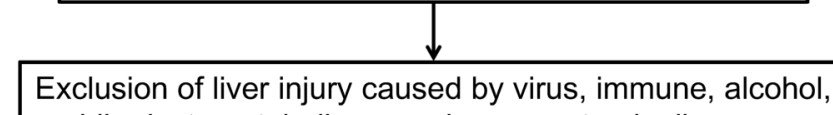
bile duct, metabolic, vascular, or systemic diseases

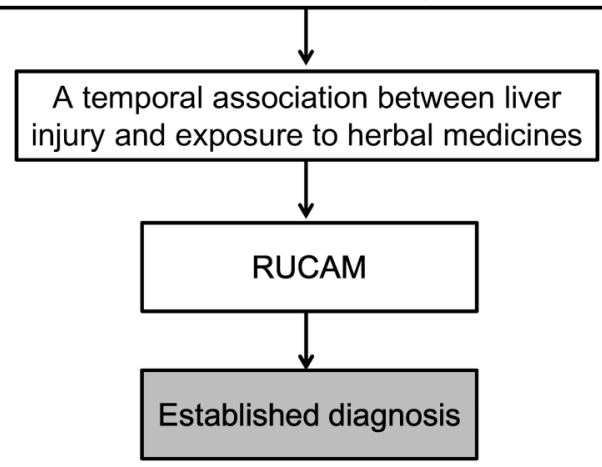

Fig. 1. Flowchart depicting the diagnosis strategy of herb induced liver injury, adapted from the Chinese guidelines for the diagnosis and management of herb-induced liver injury. ${ }^{106}$ Thresholds of ALT and ALP are in line with the updated RUCAM. ${ }^{15}$ Establishing the RUCAM-based diagnosis of HILI requires RUCAM scores of $\geq 6$ that provide causality gradings of probable or highly probable. Additional search for herbal authentications, adulterations, toxin contaminations, and biomarkers may be needed. ${ }^{106}$

Abbreviations: ALP, alkaline phosphatase; ALT, alanine aminotransferase; RUCAM, Roussel Uclaf Causality Assessment Method; ULN, upper limit of normal. 
criteria are identical, others are variable. ${ }^{106-108}$ Therefore, and in future guidelines, some uniformity is desired to facilitate their use. This should include separate listing of RUCAMbased HILI and DILI cases without using concomitantly a non-RUCAM method to avoid confusion, providing RUCAMbased causality gradings for each case (Table 1), identical LT thresholds and liver pattern criteria, evaluating liver injury cases for typical features only if high causality grades such as highly probable or probable have been achieved, and the prospective use of the updated RUCAM with quotation of the corresponding publication. ${ }^{15}$ New guidelines should specifically address only diagnostic recommendations using the updated RUCAM and not include clinical data like general liver injury features unless derived from cases assessed for causality by RUCAM with high causality gradings.

Guidelines with the updated RUCAM should also be used for evaluation of liver injury in patients with COVID-19 infections to analyze whether the injury is caused by the virus itself (found in the liver) ${ }^{109,110}$ by other factors such as pre-existing liver disease, ${ }^{18,33,36}$ or the use of potentially hepatotoxic conventional drugs or herbal TCMs, ${ }^{33}$ conditions well described in publications from China. ${ }^{18,11,36}$ Finally, since acute respiratory syndrome is a severe complication in these patients, the liver injury could be caused by respiratory insufficiency leading to respiratory hepatopathy due to hepatic hypoxia, in analogy to cardiac hepatopathy, as detailed earlier ${ }^{11,112}$ and listed as important differential diagnosis of HILI and DILI. ${ }^{15}$

\section{Conclusions}

In Asian countries, herbal medicines are part of the national health system and in use for many centuries, obviously without major problems. More recently, however, much attention has been paid to their adverse effects on the liver. Proposals include: (1) diagnosis of HILI should be improved alongside guidelines that incorporate current ALT thresholds and the use of the updated RUCAM to validly assess causality; (2) for study purposes, a prospective design is urgently needed to prevent fruitless discussions on poor quality HILI publications; and (3) randomized-controlled trials are needed to establish a good benefit over risk balance for safe use by consumers.

\section{Funding}

None to declare.

\section{Conflict of interest}

The authors have no conflict of interests related to this publication.

\section{Author contributions}

Study concept and design (RT, YZ), acquisition of data (YZ, $\mathrm{JJ})$, analysis and interpretation of data (RT, $Y Z, J J)$, drafting of the manuscript (RT), critical revision of the manuscript for important intellectual content $(Y Z, J J)$.

\section{References}

[1] Teschke R, Schwarzenboeck A, Schmidt-Taenzer W, Wolff A, Hennermann $\mathrm{KH}$. Herb induced liver injury presumably caused by black cohosh: a survey of initially purported cases and herbal quality specifications. Ann Hepatol 2011;10:249-259. doi: 10.1016/S1665-2681(19)31536-4.

[2] Teschke R, Glass X, Schulze J. Herbal hepatotoxicity by Greater Celandine (Chelidonium majus): causality assessment of 22 spontaneous reports. Regul Toxicol Pharmacol 2011;61:282-291. doi: 10.1016/j.yrtph.2011. 08.008 .

[3] Brown AC. Liver toxicity related to herbs and dietary supplements: Online table of case reports. Part 2 of 5 series. Food Chem Toxicol 2017;107:472501. doi: 10.1016/j.fct.2016.07.001.

[4] Meunier L, Larrey D. Drug-induced liver injury: Biomarkers, requirements, candidates, and validation. Front Pharmacol 2019;10:1482. doi: 10. 3389/fphar.2019.01482.

[5] Teschke R, Eickhoff A, Schulze J. Drug- and herb-induced liver injury in clinical and translational hepatology: Causality assessment methods, Quo Vadis? J Clin Transl Hepatol 2013;1:59-74. doi: 10.14218/JCTH.2013. D002X.

[6] Teschke R, Wolff A, Frenzel C, Schwarzenboeck A, Schulze J, Eickhoff A. Drug and herb induced liver injury: Council for International Organizations of Medical Sciences scale for causality assessment. World J Hepatol 2014;6: 17-32. doi: 10.4254/wjh.v6.i1.17.

[7] Sarges P, Steinberg JM, Lewis JH. Drug-induced liver injury: Highlights from a review of the 2015 literature. Drug Saf 2016;39:801-821. doi: 10. 1007/s40264-016-0427-8.

[8] Shahbaz O, Mahajan S, Lewis JH. Highlights of drug - and herb- induced liver injury in the literature from 2016: how best to translate new information into clinical practice? Expert Opin Drug Metab Toxicol 2017;13:935-951. doi: 10.1080/17425255.2017.1362391.

[9] Real M, Barnhill MS, Higley C, Rosenberg J, Lewis JH. Drug-induced liver injury: Highlights of the recent literature. Drug Saf 2019;42:365-387. doi: $10.1007 / \mathrm{s} 40264-018-0743-2$.

[10] Teschke R, Melchart D, Xuan TD. Hormesis and dose-responses in herbal traditional Chinese medicine (TCM) alone are insufficient solving real clinical TCM challenges and associated herbal quality issues. Longhua Chin Med 2018;1:3. doi: $10.21037 / \mathrm{lcm} .2018 .03 .01$.

[11] Teschke R. Idiosyncratic DILI: Analysis of 46,266 cases assessed for causality by RUCAM and published from 2014 to early 2019. Front Pharmacol 2019;10:730. doi: 10.3389/fphar.2019.00730.

[12] Danan G, Benichou C. Causality assessment of adverse reactions to drugsI. A novel method based on the conclusions of international consensus meetings: application to drug-induced liver injuries. J Clin Epidemiol 1993;46:1323-1330. doi: 10.1016/0895-4356(93)90101-6.

[13] Benichou C, Danan G, Flahault A. Causality assessment of adverse reactions to drugs-II. An original model for validation of drug causality assessment methods: case reports with positive rechallenge. J Clin Epidemiol 1993;46: 1331-1336. doi: 10.1016/0895-4356(93)90102-7.

[14] Bénichou C. Criteria of drug-induced liver disorders. Report of an international consensus meeting. J Hepatol 1990;11:272-276. doi: 10. 1016/0168-8278(90)90124-a.

[15] Danan G, Teschke R. RUCAM in drug and herb induced liver injury: The update. Int J Mol Sci 2015;17:14. doi: 10.3390/ijms17010014.

[16] Danan G, Teschke R. Drug-induced liver injury: Why is the roussel uclaf causality assessment method (RUCAM) still used 25 years after its launch? Drug Saf 2018;41:735-743. doi: 10.1007/s40264-018-0654-2.

[17] Danan G, Teschke R. Roussel uclaf causality assessment method for druginduced liver injury: Present and future. Front Pharmacol 2019;10:853. doi: 10.3389/fphar.2019.00853.

[18] Yuen MF, Tam S, Fung J, Wong DK, Wong BC, Lai CL. Traditional Chinese medicine causing hepatotoxicity in patients with chronic hepatitis B infection: a 1-year prospective study. Aliment Pharmacol Ther 2006;24:11791186. doi: 10.1111/j.1365-2036.2006.03111.x.

[19] Cheung WI, Tse ML, Ngan T, Lin J, Lee WK, Poon WT, et al. Liver injury associated with the use of Fructus Psoraleae (Bol-gol-zhee or Bu-gu-zhi) and its related proprietary medicine. Clin Toxicol (Phila) 2009;47:683685. doi: 10.1080/15563650903059136.

[20] Nin Chau T, Cheung WI, Ngan T, Lin J, Lee KW, Tat Poon W, et al. Causality assessment of herb-induced liver injury using multidisciplinary approach and Roussel Uclaf Causality Assessment Method (RUCAM). Clin Toxicol (Phila) 2011;49:34-39. doi: 10.3109/15563650.2010.537662.

[21] Lin G, Wang JY, Li N, Li M, Gao H, Ji Y, et al. Hepatic sinusoidal obstruction syndrome associated with consumption of Gynura segetum. J Hepatol 2011;54:666-673. doi: 10.1016/j.jhep.2010.07.031.

[22] Gao H, Li N, Wang JY, Zhang SC, Lin G. Definitive diagnosis of hepatic sinusoidal obstruction syndrome induced by pyrrolizidine alkaloids. J Dig Dis 2012;13:33-39. doi: 10.1111/j.1751-2980.2011.00552.x.

[23] Dong H, Slain D, Cheng J, Ma W, Liang W. Eighteen cases of liver injury following ingestion of Polygonum multiflorum. Complement Ther Med 2014;22:70-74. doi: 10.1016/j.ctim.2013.12.008.

[24] Hao K, Yu Y, He C, Wang M, Wang S, Li X. RUCAM scale-based diagnosis, clinical features and prognosis of 140 cases of drug-induced liver injury. 
Zhonghua Gan Zang Bing Za Zhi 2014;22:938-941. doi: 10.3760/cma.j. issn.1007-3418.2014.12.012.

[25] Gao H, Ruan JQ, Chen J, Li N, Ke CQ, Ye Y, et al. Blood pyrrole-protein adducts as a diagnostic and prognostic index in pyrrolizidine alkaloidhepatic sinusoidal obstruction syndrome. Drug Des Devel Ther 2015;9: 4861-4868. doi: 10.2147/DDDT.S87858.

[26] Ou P, Chen Y, Li B, Zhang M, Liu X, Li F, et al. Causes, clinical features and outcomes of drug-induced liver injury in hospitalized patients in a Chinese tertiary care hospital. Springerplus 2015;4:802. doi: 10.1186/s40064015-1600-8.

[27] Wang J, Ma Z, Niu M, Zhu Y, Liang Q, Zhao Y, et al. Evidence chain-based causality identification in herb-induced liver injury: exemplification of a well-known liver-restorative herb Polygonum multiflorum. Front Med 2015;9:457-467. doi: 10.1007/s11684-015-0417-8.

[28] Zhu Y, Liu SH, Wang JB, Song HB, Li YG, He T, et al. Clinical analysis of drug-induced liver injury caused by polygonum multiflorum and its preparations. Zhongguo Zhong Xi Yi Jie He Za Zhi 2015;35:1442-1447.

[29] Zhang P, Ye Y, Yang X, Jiao Y. Systematic review on Chinese herbal medicine induced liver injury. Evid Based Complement Alternat Med 2016;2016: 3560812. doi: $10.1155 / 2016 / 3560812$.

[30] Zhu Y, Niu M, Chen J, Zou ZS, Ma ZJ, Liu SH, et al. Hepatobiliary and pancreatic: Comparison between Chinese herbal medicine and Western medicine-induced liver injury of 1985 patients. J Gastroenterol Hepatol 2016. 31:1476-1482. doi: 10.1111/jgh.13323.

[31] Li CY, He Q, Gao D, Li RY, Zhu Y, Li HF, et al. Idiosyncratic drug-induced liver injury linked to Polygonum multiflorum: A case study by pharmacognosy. Chin J Integr Med 2017;23:625-630. doi: 10.1007/s11655-017-2543-9.

[32] Chow HC, So TH, Choi HCW, Lam KO. Literature review of traditional Chinese medicine herbs-induced liver injury from an oncological perspective with RUCAM. Integr Cancer Ther 2019;18:1534735419869479. doi: $10.1177 / 1534735419869479$.

[33] Jing J, Wang RL, Zhao XY, Zhu Y, Niu M, Wang LF, et al. Association between the concurrence of pre-existing chronic liver disease and worse prognosis in patients with an herb- Polygonum multiflorum thunb. induced liver injury: a case-control study from a specialised liver disease center in China. BM] Open 2019;9:e023567. doi: 10.1136/bmjopen-2018-023567.

[34] Li A, Gao M, Zhao N, Li P, Zhu J, Li W. Acute liver failure associated with Fructus Psoraleae: a case report and literature review. BMC Complement Altern Med 2019;19:84. doi: 10.1186/s12906-019-2493-9.

[35] Liu Y, Wang W, Sun M, Ma B, Pang L, Du Y, et al. Polygonum multifloruminduced liver injury: Clinical characteristics, risk factors, material basis, action mechanism and current challenges. Front Pharmacol 2019;10: 1467. doi: 10.3389/fphar.2019.01467.

[36] Shen T, Liu Y, Shang J, Xie Q, Li J, Yan M, et al. Incidence and etiology of drug-induced liver injury in mainland China. Gastroenterology 2019;156: 2230-2241.e11. doi: 10.1053/j.gastro.2019.02.002.

[37] Tan Y, Chen H, Zhou X, Sun L. RUCAM-based assessment of liver injury by xiang-tian-guo (Swietenia macrophylla) seeds, a plant used for treatment of hypertension and diabetes. Ann Hepatol 2019;18:406-407. doi: 10. 1016/j.aohep.2019.01.003.

[38] Zhu Y, Niu M, Wang JB, Wang RL, Li JY, Ma YQ, et al. Predictors of poor outcomes in 488 patients with herb-induced liver injury. Turk J Gastroenterol 2019;30:47-58. doi: 10.5152/tjg.2018.17847.

[39] Tsuda T, Yashiro S, Gamo Y, Watanabe K, Hoshino T, Oikawa T, et al. Discrepancy between clinical course and drug-induced lymphocyte stimulation tests in a case of saireito-induced liver injury accompanied by Sjögren syndrome. J Altern Complement Med 2010;16:501-505. doi: 10.1089/acm. 2009.0183.

[40] Ahn BM. Herbal preparation-induced liver injury. Korean J Gastroenterol 2004;44:113-125.

[41] Seo JC, Jeon WJ, Park SS, Kim SH, Lee KM, Chae HB, et al. Clinical experience of 48 acute toxic hepatitis patients. Korean J Hepatol 2006;12:74-81.

[42] Kang SH, Kim JI, Jeong KH, Ko KH, Ko PG, Hwang SW, et al. Clinical characteristics of 159 cases of acute toxic hepatitis. Korean J Hepatol 2008;14: 483-492. doi: 10.3350/kjhep.2008.14.4.483.

[43] Sohn CH, Cha MI, Oh BJ, Yeo WH, Lee JH, Kim W, et al. Liver transplantation for acute toxic hepatitis due to herbal medicines and preparations. J Korean Soc Clin Toxicol 2008;6:110-116.

[44] Kang HS, Choi HS, Yun TJ, Lee KG, Seo YS, Yeon JE, et al. A case of acute cholestatic hepatitis induced by Corydalis speciosa Max. Korean J Hepatol 2009;15:517-523. doi: 10.3350/kjhep.2009.15.4.517.

[45] Kim SY, Yim HJ, Ahn JH, Kim JH, Kim JN, Yoon I, et al. Two cases of toxic hepatitis caused by arrowroot juice. Korean J Hepatol 2009;15:504-509. doi: $10.3350 / \mathrm{kjhep} .2009 .15 .4 .504$.

[46] Bae SH, Kim DH, Bae YS, Lee KJ, Kim DW, Yoon JB, et al. Toxic hepatitis associated with Polygoni multiflori. Korean J Hepatol 2010;16:182-186. doi: 10.3350/kjhep.2010.16.2.182.

[47] Yang HN, Kim DJ, Kim YM, Kim BH, Sohn KM, Choi MJ, et al. Aloe-induced toxic hepatitis. J Korean Med Sci 2010;25:492-495. doi: 10.3346/jkms. 2010.25.3.492.
[48] Jung KA, Min HJ, Yoo SS, Kim HJ, Choi SN, Ha CY, et al. Drug-induced liver injury: Twenty five cases of acute hepatitis following ingestion of polygonum multiflorum thunb. Gut Liver 2011;5:493-499. doi: 10.5009/gnl. 2011.5.4.493.

[49] Kim Y], Ryu SL, Shim JW, Kim DS, Shim JY, Park MS, et al. A pediatric case of toxic hepatitis induced by Hovenia dulcis. Pediatr Gastroenterol Hepatol Nutr 2012;15:111-116. doi: 10.5223/pghn.2012.15.2.111.

[50] Suk KT, Kim DJ, Kim CH, Park SH, Yoon JH, Kim YS, et al. A prospective nationwide study of drug-induced liver injury in Korea. Am J Gastroenterol 2012;107:1380-1387. doi: 10.1038/ajg.2012.138.

[51] Lee J, Shin JS, Kim MR, Byun JH, Lee SY, Shin YS, et al. Liver enzyme abnormalities in taking traditional herbal medicine in Korea: A retrospective large sample cohort study of musculoskeletal disorder patients. J Ethnopharmacol 2015;169:407-412. doi: 10.1016/j.jep.2015.04.048.

[52] Lee WJ, Kim HW, Lee HY, Son CG. Systematic review on herb-induced liver injury in Korea. Food Chem Toxicol 2015;84:47-54. doi: 10.1016/j.fct. 2015.06.004.

[53] Woo HJ, Kim HY, Choi ES, Cho YH, Kim Y, Lee JH, et al. Drug-induced liver injury: A 2-year retrospective study of 1169 hospitalized patients in a single medical center. Phytomedicine 2015;22:1201-1205. doi: 10.1016/j. phymed.2015.10.002.

[54] Cho JH, Oh DS, Hong SH, Ko H, Lee NH, Park SE, et al. A nationwide study of the incidence rate of herb-induced liver injury in Korea. Arch Toxicol 2017; 91:4009-4015. doi: 10.1007/s00204-017-2007-9.

[55] Wai CT. Presentation of drug-induced liver injury in Singapore. Singapore Med J 2006;47:116-120.

[56] Teo DC, Ng PS, Tan SH, Lim AT, Toh DS, Chan SY, et al. Drug-induced liver injury associated with Complementary and Alternative Medicine: a review of adverse event reports in an Asian community from 2009 to 2014. BMC Complement Altern Med 2016;16:192. doi: 10.1186/s12906-016-1168-z.

[57] Teschke R, Bahre R. Severe hepatotoxicity by Indian Ayurvedic herbal products: a structured causality assessment. Ann Hepatol 2009;8:258-266. doi: 10.1016/S1665-2681(19)31777-6.

[58] Dalal KK, Holdbrook T, Peikin SR. Ayurvedic drug induced liver injury. World J Hepatol 2017;9:1205-1209. doi: 10.4254/wjh.v9.i31.1205.

[59] Ruknuddin G. Do Ayurveda drugs induce liver injury? World J Hepatol 2018; 10:400-401. doi: 10.4254/wjh.v10.i3.400.

[60] Bunchorntavakul C, Reddy KR. Review article: herbal and dietary supplement hepatotoxicity. Aliment Pharmacol Ther 2013;37:3-17. doi: 10. 1111/apt.12109.

[61] Philips CA, Augustine P, Rajesh S, Y PK, Madhu D. Complementary and alternative medicine-related drug-induced liver injury in Asia. J Clin Transl Hepatol 2019;7:263-274. doi: 10.14218/JCTH.2019.00024.

[62] Rathi C, Pipaliya N, Patel R, Ingle M, Phadke A, Sawant P. Drug induced liver injury at a tertiary hospital in india: etiology, clinical features and predictors of mortality. Ann Hepatol 2017;16:442-450. doi: 10.5604/16652681. 1235488.

[63] Teschke R, Danan G. Prospective Indian study of DILI with confirmed causality using the roussel uclaf causality assessment method (RUCAM): A report of excellence. Ann Hepatol 2017;16:324-325. doi: 10. $5604 / 16652681.1235471$.

[64] Devarbhavi H. Ayurvedic and herbal medicine-induced liver injury: It is time to wake up and take notice. Indian J Gastroenterol 2018;37:5-7. doi: 10. 1007/s12664-018-0820-6.

[65] Teschke R, Eickhoff A, Brown AC, Neuman MG, Schulze J. Diagnostic biomarkers in liver injury by drugs, herbs, and alcohol: Tricky dilemma after EMA correctly and officially retracted letter of support. Int J Mol Sci 2019; 21:212. doi: 10.3390/ijms21010212

[66] Wang R, Qi X, Yoshida EM, Méndez-Sánchez N, Teschke R, Sun M, et al. Clinical characteristics and outcomes of traditional Chinese medicineinduced liver injury: a systematic review. Expert Rev Gastroenterol Hepatol 2018;12:425-434. doi: 10.1080/17474124.2018.1427581.

[67] Zhu J, Chen M, Borlak J, Tong W. The landscape of hepatobiliary adverse reactions across 53 herbal and dietary supplements reveals immune-mediated injury as a common cause of hepatitis. Arch Toxicol 2020;94:273-293. doi: 10.1007/s00204-019-02621-4

[68] Teschke R., Danan G. Causality assessment methods in drug-induced liver injury. In: Chen M, Will $Y$, editors. Drug-induced liver toxicity. Methods in pharmacology and toxicology. New York: Humana; 2018. doi: 10. 1007/978-1-4939-7677-5_27.

[69] Björnsson ES. Hepatotoxicity by drugs: The most common implicated agents. Int J Mol Sci 2016;17:224. doi: 10.3390/ijms17020224.

[70] Björnsson ES, Hoofnagle JH. Categorization of drugs implicated in causing liver injury: Critical assessment based on published case reports. Hepatology 2016;63:590-603. doi: 10.1002/hep.28323.

[71] Teschke R. Top-ranking drugs out of 3312 drug-induced liver injury cases evaluated by the Roussel Uclaf Causality Assessment Method. Expert Opin Drug Metab Toxicol 2018;14:1169-1187. doi: 10.1080/17425255.2018. 1539077. 
[72] Yang H, Guo D, Xu Y, Zhu M, Yao C, Chen C, et al. Comparison of different liver test thresholds for drug-induced liver injury: Updated RUCAM versus other methods. Front Pharmacol 2019;10:816. doi: 10.3389/fphar.2019. 00816.

[73] Lee J, Shin JS, Lee YJ, Kim MR, Shin BC, Lee JH, et al. Battle over herbinduced liver injury: Low prevalence confirmed through secondary evaluation and research team's clarifying rebuttal to unwarranted public claims. J Altern Complement Med 2019:25:260-264 doi: 10.1089/acm.2018.0253.

[74] Suh JI. Drug-induced liver injury. Yeungnam Univ ] Med 2020;37:2-12. doi: 10.12701/yujm.2019.00297.

[75] Teschke R, Schwarzenboeck A, Frenzel C, Schulze J, Eickhoff A, Wolff A. The mystery of the Hawaii liver disease cluster in summer 2013: A pragmatic and clinical approach to solve the problem. Ann Hepatol 2016;15:91-109. doi: $10.5604 / 16652681.1184237$.

[76] Teschke R, Eickhoff A. The honolulu liver disease cluster at the medical center: Its mysteries and challenges. Int J Mol Sci 2016;17:476. doi: 10 . 3390/ijms17040476.

[77] Melchart D, Hager S, Albrecht S, Dai J, Weidenhammer W, Teschke R. Herbal Traditional Chinese Medicine and suspected liver injury: A prospective study. World J Hepatol 2017;9:1141-1157. doi: 10.4254/wjh.v9.i29.1141.

[78] Zhou Y, Yang L, Liao Z, He X, Zhou Y, Guo H. Epidemiology of drug-induced liver injury in China: a systematic analysis of the Chinese literature including 21,789 patients. Eur J Gastroenterol Hepatol 2013;25:825-829. doi: 10.1097/MEG.0b013e32835f6889.

[79] Teschke R, Eickhoff A, Wolff A, Xuan TD. Liver injury from herbs and "dietary supplements": Highlights of a literature review from 2015 to 2017. Curr Pharmacol Rep 2018;4:120-131. doi: 10.1007/s40495-018-0124-7.

[80] Teschke R, Eickhoff A, Schwarzenboeck A, Schmidt-Taenzer W, Genthner A, Frenzel $C$, et al. Clinical review: Herbal hepatotoxicity and the call for systematic data documentation of individual cases. J Liver Clin Res 2015;2 1008.

[81] Teschke R, Andrade RJ. Drug, Herb, and Dietary Supplement Hepatotoxicity. Int J Mol Sci 2016;17:1488. doi: 10.3390/ijms17091488.

[82] Dakhiya Y, Hussien D, Fridman E, Kiflawi M, Green R. Correlations between circadian rhythms and growth in challenging environments. Plant Physio 2017;173:1724-1734. doi: 10.1104/pp.17.00057.

[83] Xuan TD, Khanh TD, Khang DT, Quan NT, Elzaawely AA. Changes in chemical composition, total phenolics and antioxidant activity of Alpinia (Alpinia zerumbet) leaves exposed to UV. Intern Lett Nat Sci 2016;55:25-34. doi: 10. 18052/www.scipress.com/ILNS.55.25.

[84] Cha JY, Khaleda L, Park HJ, Kim WY. A chaperone surveillance system in plant circadian rhythms. BMB Rep 2017;50:235-236. doi: 10. 5483/bmbrep.2017.50.5.064.

[85] Elzaawely AA, Xuan TD, Tawata S. Changes in essential oils, kava pyrones and total phenolics of Alpinia zerumbet (Pers.) B.L. Burtt. \& R.M. Sm. leaves exposed to copper sulphate. Environ Experiment Botany 2007;59:347353. doi: 10.1016/j.envexpbot.2006.04.007.

[86] Vongdala N, Tran HD, Xuan TD, Teschke R, Khanh TD. Heavy metal accumulation in water, soil, and plants of municipal solid waste landfill in Vientiane, Laos. Int J Environ Res Public Health 2018;16:22. doi: 10. 3390/ijerph16010022.

[87] Tong K, Li ZL, Sun X, Yan S, Jiang MJ, Deng MS, et al. Metabolomics approach reveals annual metabolic variation in roots of Cyathula officinalis Kuan based on gas chromatography-mass spectrum. Chin Med 2017;12: 12. doi: 10.1186/s13020-017-0133-1.

[88] Lin L, Li H, Lin H, Zhang M, Qu C, Yan L, et al. A new perspective on liver injury by traditional Chinese herbs such as Polygonum multiflorum: The geographical area of harvest as an important contributory factor. Front Pharmacol 2017;8:349. doi: 10.3389/fphar.2017.00349.

[89] Frenzel C, Teschke R. Herbal hepatotoxicity: Clinical characteristics and listing compilation. Int $\mathrm{J}$ Mol Sci 2016;17:588. doi: 10 . 3390/ijms17050588.

[90] Teschke R, Larrey D, Melchart D, Danan G. Traditional chinese medicine (TCM) and herbal hepatotoxicity: RUCAM and the role of novel diagnostic biomarkers such as microRNAs. Medicines (Basel) 2016;3:18. doi: 10. 3390/medicines3030018.
[91] Teschke R. Traditional Chinese medicine induced liver injury. J Clin Transl Hepatol 2014;2:80-94. doi: 10.14218/JCTH.2014.00003.

[92] Teschke R, Wolff A, Frenzel C, Schulze J. Review article: Herbal hepatotoxicity-an update on traditional Chinese medicine preparations. Aliment Pharmacol Ther 2014;40:32-50. doi: 10.1111/apt.12798.

[93] Teschke R, Zhang L. Chinese herbs and their molecules: Clinical and pathophysiological implications for the liver. J Mol Pathophysiol 2015;4:85-92. doi: $10.5455 /$ jmp. 20150710032817.

[94] Teschke R, Eickhoff A. Herbal hepatotoxicity in traditional and modern medicine: actual key issues and new encouraging steps. Front Pharmacol 2015 6:72. doi: 10.3389/fphar.2015.00072.

[95] Teschke R, Zhang L, Long $H$, Schwarzenboeck A, Schmidt-Taenzer W, Genthner A, et al. Traditional Chinese Medicine and herbal hepatotoxicity: a tabular compilation of reported cases. Ann Hepatol 2015;14:7-19. doi: 10.1016/S1665-2681(19)30796-3.

[96] Zhu J, Seo JE, Wang S, Ashby K, Ballard R, Yu D, et al. The development of a database for herbal and dietary supplement induced liver toxicity. Int $\mathrm{J}$ Mol Sci 2018;19:2955. doi: 10.3390/ijms19102955.

[97] Mazzanti G, Di Sotto A, Vitalone A. Hepatotoxicity of green tea: an update. Arch Toxicol 2015;89:1175-1191. doi: 10.1007/s00204-015-1521-x.

[98] Teschke R, Xuan TD. Suspected herb induced liver injury by green tea extracts: Critical review and case analysis applying RUCAM for causality assessment. Jap J Gastroenterol Hepatol 2019;1:1-16.

[99] Oketch-Rabah HA, Roe AL, Rider CV, Bonkovsky HL, Giancaspro GI, Navarro $V$, et al. United States Pharmacopeia (USP) comprehensive review of the hepatotoxicity of green tea extracts. Toxicol Rep 2020;7:386-402. doi: 10. 1016/j.toxrep.2020.02.008.

[100] Hong M, Li S, Tan HY, Cheung F, Wang N, Huang J, et al. A network-based pharmacology study of the herb-induced liver injury potential of traditional hepatoprotective Chinese herbal medicines. Molecules 2017;22:632. doi: $10.3390 /$ molecules22040632.

[101] Xu Y, Patel DN, Ng SP, Tan SH, Toh D, Poh J, et al. Retrospective study of reported adverse events due to complementary health products in Singapore from 2010 to 2016. Front Med (Lausanne) 2018;5:167. doi: 10. 3389/fmed.2018.00167.

[102] Yang M, Li Z, Dou D. Can retrospective studies confirm causes of druginduced liver injury? Gastroenterology 2019;157:1436-1437. doi: 10. 1053/j.gastro.2019.03.078.

[103] Devarbhavi $\mathrm{H}$, Bjornsson ES. RE: Incidence and etiology of drug-induced liver injury in mainland China. Gastroenterology 2019;157:1437-1438. doi: 10.1053/j.gastro.2019.06.045.

[104] Cong W, Xin Q, Gao Y. RE: Incidence and etiology of drug-induced liver injury in mainland China. Gastroenterology 2019;157:1438-1439. doi: 10.1053/j.gastro.2019.05.076.

[105] Shen T, Mao Y, Chen C. Reply. Gastroenterology 2019;157:1439-1440. doi: $10.1053 / j$.gastro.2019.08.047.

[106] Wang JB, Zhu Y, Bai ZF, Wang FS, Li XH, Xiao XH. Guidelines for the diagnosis and management of herb-induced liver injury. Chin J Integr Med 2018;24:696-706. doi: 10.1007/s11655-018-3000-8.

[107] Xiao X, Tang J, Mao Y, Li X, Wang J, Liu C, et al. Guidance for the clinical evaluation of traditional Chinese medicine-induced liver injuryIssued by China Food and Drug Administration. Acta Pharm Sin B 2019;9:648-658. doi: 10.1016/j.apsb.2018.12.003.

[108] Yu YC, Mao YM, Chen CW, Chen J], Chen J, Cong WM, et al. CSH guidelines for the diagnosis and treatment of drug-induced liver injury. Hepatol Int 2017;11:221-241. doi: 10.1007/s12072-017-9793-2.

[109] Xu L, Liu J, Lu M, Yang D, Zheng X. Liver injury during highly pathogenic human coronavirus infections. Liver Int 2020. doi: 10.1111/liv.14435.

[110] Zhang C, Shi L, Wang FS. Liver injury in COVID-19: management and challenges. Lancet Gastroenterol Hepatol 2020. doi: 10.1016/S2468-1253(20) 30057-1.

[111] Byrne TJ, Parish JM, Somers V, Aqel BA, Rakela J. Evidence for liver injury in the setting of obstructive sleep apnea. Ann Hepatol 2012;11:228-231. doi: 10.1016/S1665-2681(19)31028-2.

[112] Henrion J. Hypoxic hepatitis. Liver Int 2012;32:1039-1052. doi: 10. $1111 / \mathrm{j} .1478-3231.2011 .02655 . x$. 